\title{
Successful conservative management of live cervical ectopic pregnancy: case report
}

\author{
Juhi L. Khithani*, Pradnya B. Supe, Meenal S. Sarmalkar
}

Department of Obstretrics and Gynaecology, Lokmanya Tilak Municipal Medical College, Mumbai, Maharashtra, India

Received: 19 August 2020

Accepted: 29 September 2020

\section{*Correspondence:}

Dr. Juhi L. Khithani,

E-mail: juhikhithani@gmail.com

Copyright: (c) the author(s), publisher and licensee Medip Academy. This is an open-access article distributed under the terms of the Creative Commons Attribution Non-Commercial License, which permits unrestricted non-commercial use, distribution, and reproduction in any medium, provided the original work is properly cited.

\begin{abstract}
Cervical ectopic pregnancy (CEP) is an exceptional type of ectopic pregnancy, representing < $1 \%$ of the ectopic pregnancy with incidence 1:2500 to 1:12000. It can lead to life threatening complication and torrential bleeding and even necessitate the need for hysterectomy. A 30-year-old patient referred to Lokmanya Tilak Municipal Medical College with transvaginal sonography suggestive of live CEP. Because of patient's stable condition, it was treated with ultrasound-guided intra-amniotic methotrexate administration. Day $1 \beta$-HCG was 4200 IU/L, day 10489 IU/L. Gradual decrease of $\beta-\mathrm{HCG}$ levels was coinciding with ultrasonographic finding of absence of gestational sac. During hospitalization, patient reported only minimal vaginal spotting on day 3 of treatment and discharged on day 10 with weekly $\beta$-HCG followup. CEP was managed conservatively without surgical intervention, preserving patient's fertility. Timely detection of CEP and prompt action can save patients fertility with minimal or no surgical intervention.
\end{abstract}

Keywords: Cervical ectopic pregnancy, Intraamniotic methotrexate injection, Transvaginal ultrasonography, Conservative management

\section{INTRODUCTION}

Ectopic pregnancy is the leading cause of maternal mortality in the first trimester. Cervical ectopic is an exceptional form of non-tubal ectopic \& represents $<1 \%$ of the ectopic pregnancy with incidence 1:2500 to 1:12000. ${ }^{1}$ It can lead to life threatening complication and torrential bleeding and even necessitate the need for hysterectomy. No consensus has yet been achieved for the optimal therapeutic management of cervical pregnancy as the rarity of cases poses scientific limitations for the management. There is a shift of modern clinical practice that has led to the development of more conservative treatments that attempt to limit morbidity and preserve fertility. ${ }^{1-3}$
Cervical glands are opposite the trophoblastic tissue, the trophoblastic attachment is below the entrance of the uterine vessels to the uterus, and fetal elements are absent from the uterine corpus This confirms the diagnosis of a rare presentation of cervical pregnancy based on Rubin's criteria. $^{4}$

The exact cause of cervical pregnancy is not known. The accelerated migration of the fertilized ovum through the uterus and the change in the ability of the endometrial lining to accept implantation and damage to the endometrial canal may all be the contributing factor. ${ }^{1,2}$

Palmaan et al had proposed clinical criteria for diagnosing this condition. ${ }^{5}$ Uterine bleeding without cramping pain following a period of amenorrhea, hourglass-shaped uterus, partly open external os, closed 
internal os, products of conception entirely confined within the cervix and firmly attached to the endocervix.

Ultrasound criteria were empty uterus, hourglass shape of uterus, ballooned out cervical canal, gestational sac and placental tissue in the cervical canal, closed internal os and sliding sign absent. ${ }^{6}$

\section{CASE REPORT}

A 30-year-old patient was referred in emergency, admitted at Lokmanya Tilak Municipal Medical College, Department of obstetrics and gynacology with a transvaginal ultrasonography (TVS) of cervical ectopic pregnancy and $(\beta-\mathrm{HCG})$ beta human chorionic gonadotropine $2150 \mathrm{mIU} / \mathrm{mL}$ on $52 \mathrm{nd}$ day of her last menstrual cycle. Conception was spontaneous. The patient had an obstetrical history of one pregnancy, which was complete spontaneous abortion and no check curettage was done for the same. Regarding medicalgynecological history, patient had two fibroids measuring about $4 \times 4 \mathrm{~cm}$ in the posterior uterine wall and fundus respectively.

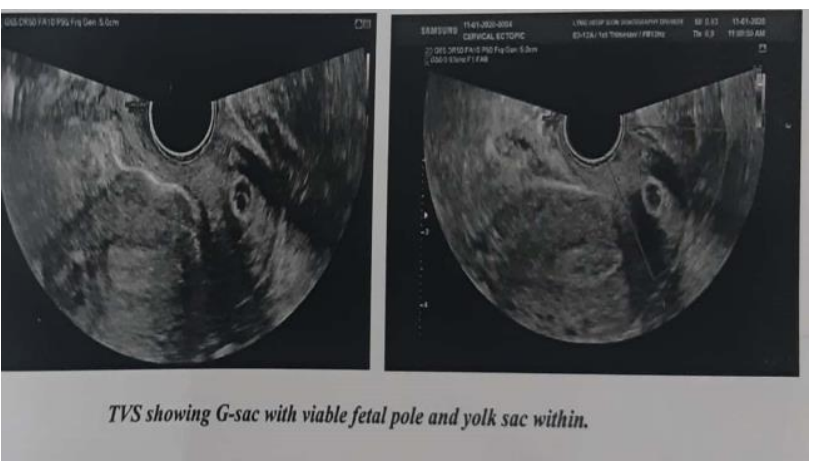

Figure 1: TVS showing G-sac with viable fetal pole and yolk sac within.

During her physical and gynecological examination patient was hemodynamically stable. Per abdominally was soft no guarding, tenderness, or rigidity felt. On pelvic examination, per speculum examination cervix and vagina were healthy no bleeding or spotting seen. Per vaginally uterus was bulky and ballooned-out cervix. Bilateral fornices were free and no tenderness was felt. TVS (Figure 1) suggestive of empty endometrial cavity, gestational $\mathrm{sac}=9 \mathrm{~cm}$ within the cervical canal $\mathrm{CRL}=$ $3 \mathrm{~mm}$. Cardiac activity was detected at the time of diagnosis. Serum $\beta-\mathrm{HCG}$ was measured $4200 \mathrm{IU} / \mathrm{L}$ on day 60th of menstrual cycle. While no other remarkable findings were observed from her blood test examination. The diagnosis of a cervical pregnancy was confirmed with MRI pelvis and patient was hospitalized for further treatment. Because of patient's stable clinical condition, with no signs of vaginal bleeding or pain, it was decided to treat the patient with ultrasound-guided intramniotic administration of methotrexate $(10 \mathrm{mg} / \mathrm{m} 2)$ using chiba double lumen 22-gauge needle. Injection of methotrexate was well tolerated by patient without need for anesthesia administration Gradual decrease of $\beta$-HCG levels was also combined with ultrasound observation of absence of gestation sac.

After treatment with intra amniotic methotrexate injection on day $1 \beta$-HCG $4200 \mathrm{IU} / \mathrm{L}$, day $2 \beta$-HCG $2844 \mathrm{IU} / \mathrm{L}$, day $4 \beta$-HCG 2225 IU/L (Figure 2).

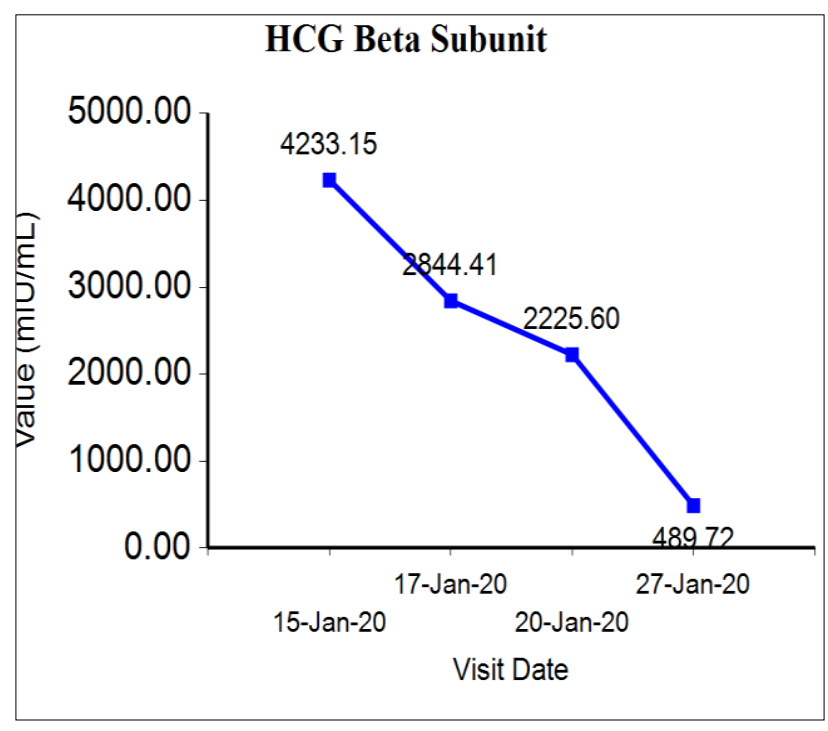

Figure 2: Beta HCG trend after intra amniotic methotrexate injection.

No additional intervention such as curettage was decided to be performed. During hospitalization period, patient reported only minimal vaginal spotting, with mild pain on day 3 and was therefore discharged on day 10 with the recommendation of follow-up on a weekly beta HCG. Her last $\beta$-HCG was $15 \mathrm{mIU} / \mathrm{ml}$ on day 28 of procedure. She got her menstrual period after 2 months of the procedure and conceived after 6 months of procedure.

\section{DISCUSSION}

Treatment options for CEP may be divided into six categories

\section{Intra-amniotic injection (locally acting agent)}

Ultrasound-guided intra-amniotic administration of potassium chloride and/or methotrexate has been used as a conservative approach for the management of CEP. Both these procedures require skill and expertise. ${ }^{7}$

\section{Systemic chemotherapy}

The most commonly used agent is methotrexate, used in a single dose or multiple doses, with or without folinic acid. However, methotrexate may be associated with bone marrow suppression, gastrointestinal disturbances and elevation of hepatic transaminases. ${ }^{7}$

\section{Tamponade with foley catheter or bakri balloon}


Use of a Foley catheter, placed gently past the external os, followed by inflation of the bulb with $30 \mathrm{~mL}$ saline has been used mostly after other techniques (e.g., curettage or methotrexate failure) result in hemorrhage. Tamponade with packing is not very useful. ${ }^{8,9}$

\section{Reduction of blood supply}

This may be undertaken by cervical cerclage, vaginal ligation of cervical arteries, uterine artery ligation, internal iliac artery ligation and angiographic embolization of the cervical, uterine or internal iliac arteries. This is usually done in preparation for surgical therapy like curettage, or along with chemotherapy, as a conservative treatment modality aimed at preserving future fertility. Embolization is primarily used as a "rescue" therapy when profuse bleeding follows other conservative methods like chemotherapy. ${ }^{11}$

\section{Surgical excision of trophoblast}

Curettage and hysterectomy are the classic methods for surgical excision of trophoblast tissue. Curettage is the age-old fertility preserving method, but risks hemorrhage. Therefore, it has been used in conjunction with mechanical methods like cervical artery ligation and tamponade.

\section{Primary hysterectomy}

It may still be the preferred modality of treatment in intractable hemorrhage, second trimester or third trimester diagnosis of CEP and possibly to avoid emergency surgery and blood transfusion in a woman not desirous of fertility. In a review, $100 \%$ of CP beyond 12 weeks' gestation ultimately required hysterectomy. ${ }^{12}$

Recently, a combination of laparoscopy-assisted uterine artery ligation followed by hysteroscopy local endocervical resection to remove CEP has been described as a fertility-preserving alternative therapy. ${ }^{13}$

As per Sunita et al the patient received conservative management by combination of intraamniotic potassium chloride and methotrexate followed by suction and curettage which prevented the need hysterectomy

As per Usha et al conservative management of cervical ectopic pregnancy was successful in preventing the need for hysterectomy in all patients in their study. In two patients with a heterotropic gestation the intrauterine pregnancy could be salvage. Their treatment protocol being intramuscular injection of methotrexate in doses between 50 to $75 \mathrm{mg} / \mathrm{m}^{2}$.

As per Domagij et al cervical ectopic can be treated by hysteroscopic resection of cervix if failed by intra amniotic injection of methotrexate
As per Tuncer et al their patient of 10 weeks cervical ectopic couldn't be given methotrexate due to having active kochs and hence was treated by dilatation and curettage due to massave hemorrhage required hysterectomy

\section{CONCLUSION}

Timely detection of CEP and prompt action can save patients fertility with minimal or no surgical intervention. We suggest that local (intra-amniotic injection of methotrexate) is ideal for patients who are stable with live cervical ectopic pregnancy particularly if gestation is less than 12 weeks, minimizing the requirement of surgical management.

\section{ACKNOWLEDGMENTS}

Dr Vivek Ukirde, Dr Rajiv Hira, Department of Radiology assisted in the procedure.

Funding: No funding sources

Conflict of interest: None declared

Ethical approval: Not required

\section{REFERENCES}

1. Prameela RC, Dev SV. Cervical ectopic pregnancy: 10 year experience at tertiary care hospital and current literature review. Int J Reprod Contracept Obstet Gynecol. 2016;3:734-42.

2. Valdez AJ, Flores SEH, Vilchis JAB, Calderon CM. Hysteroscopic treatment of cervical pregnancy: case reportInt J Reprod Contracept Obstet Gynecol. 2020 Apr;9(4):1710-2.

3. Rock JA, Damario MA. Ectopic pregnancy. In: Rock JA, Jones HW 3rd, editors.

4. Rubin IC. Cervical pregnancy. Surg Gynecol Obstet 1911;13:625-33.

5. Paalman RJ, McElin TW. Cervical pregnancy; review of the literature and presentation of cases. Am J Obstet Gynecol. 1959;77:1261-70.

6. Leeman LM, Wendland CL. Cervical ectopic pregnancy. Diagnosis with endovaginal ultrasound examination and successful treatment with methotrexate. Arch Fam Med. 2000;9:72-7.

7. Polak G, Stachowicz N, Morawska D, Kotarski J. Treatment of cervical pregnancy with systemic methotrexate and KCI solution injection into the gestational sac - Case report and review of literature. Ginekol Pol. 2011;82:386-9.

8. Grimbizis G, Chatzigeorgiou $\mathrm{K}$, Tsalikis $\mathrm{T}$, Athanasiadis A, Theodoridis T, Bontis JN. Evacuation of the cervix after methotrexate administration in the treatment of cervical pregnancy: five cases. Reprod Biomed Onlin. 2006;12:487-92.

9. Tinelli A, Malvasi A, Vergara D, Casciaro S. Emergency surgical procedure for failed methotrexate treatment of cervical pregnancy: a case 
report. Eur J Contracept Reprod Health Care. 2007;12:391-5.

10. Weibel HS, Alserri A, Reinhold C, Tulandi T. Multidose methotrexate treatment of cervical pregnancy. J Obstet Gynaecol Can. 2012;34:359-62.

11. Chen H, Yang S, Fu J, Song Y, Xiao L, Huang W, et al. Outcomes of bilateral uterine artery chemoembolization in combination with surgical evacuation or systemic methotrexate for cervical pregnancy. J Minimal Invasi Gynecol. 2015;22(6):1029-35.

12. Khatib Y, Khashikar A, Wani R, Patel RD. Cervical ectopic pregnancy: A case report of missed diagnosis. Med J DY Patil Univ. 2016;9:741-3.

13. Kung FT, Lin H, Hsu TY, Chang CY, Huang HW, Huang LY, et al. Differential diagnosis of suspected cervical pregnancy and conservative treatment with the combination of laparoscopy-assisted uterine artery ligation and hysteroscopic endocervical resection. Fertilit Sterili. 2004;81(6):1642-9.

14. TeLinde's Operative Gynaecology. USA: Lippincott Williams \& Wilkins; 2003;9:507-36.

15. Kaur Pandher D, Shehgal A. Diagnosis and management of cervical ectopic pregnancy- Report of three cases. Nepal Med Coll J. 2009;11:64-5.
16. Rizk B, Holliday CP, Owens S, Abuzeid M. Cervical and cesarean scar ectopic pregnancies: Diagnosis and management. Middle East Fertil Soc J. 2013;18:6773.

17. Yitzhak M, Orvieto R, Nitke S, Neuman-Levin M, Ben-Rafael Z, Schoenfeld A. Cervical pregnancy - A conservative stepwise approach. Hum Reprod. 1999;14:847-9.

18. Cepni I, Ocal P, Erkan S, Erzik B. Conservative treatment of cervical ectopic pregnancy with transvaginal ultrasound-guided aspiration and singledose methotrexate. Fertil Steril. 2004;81:1130-2.

19. Mashiach S, Admon D, Oelsner G, Paz B, Achiron R, Zalel Y. Cervical Shirodkar cerclage may be the treatment modality of choice for cervical pregnancy. Hum Reprod. 2002;17:493-6

20. Timor-Tritsch IE, Monteagurdo A, Mandeville EO. Successful management of viable cervical pregnancy by local injection of methotrexate guided by transvaginal ultrasonography. Am J Obstet Gynecol. 1994;17:737-9.

Cite this article as: Khithani JL, Supe PB, Sarmalkar MS. Successful conservative management of live cervical ectopic pregnancy: case report. Int J Reprod Contracept Obstet Gynecol 2020;9:4730-3. 